\title{
Management of the cardiovascular manifestations of poisoning by the Indian red scorpion (Mesobuthus tamulus)
}

\author{
H S Bawaskar, P H Bawaskar
}

\begin{abstract}
Objective-The efficacy of nifedipine and prazosin in combination or alone in the management of cardiovascular manifestations caused to Mesobuthus tamulus poisoning was investigated.

Design-Observation and study.

Setting-Hospital at Mahad, Maharashtra, India.

Subjects-62 patients who had been stung by a red scorpion were admitted from January to December 1990: 18 with hypertension, 15 with supraventricular tachycardia, 11 with pulmonary oedema, and 18 with local pain at the site of sting but no systemic involvement. Two patients with massive life-threatening pulmonary oedema were given intravenous sodium nitroprusside.

Results-The combination of nifedipine and prazosin was more successful in preventing myocardial damage in 16 patients with hypertension than was nifedipine alone in two other patients with hypertension. Prazosin alone helped to alleviate the cardiovascular manifestations in eight patients with pulmonary oedema and 15 with supraventricular tachycardia. One patient with pulmonary oedema died and two recovered after they were given intravenous sodium nitroprusside.

Conclusion-Nifedipine alone did not prevent myocardial damage unless the peripheral action of venom was blocked by prazosin.
\end{abstract}

\section{(Br Heart J 1992;68:478-80)}

Mortality from Mesobuthus (formerly Buthus or Buthotus) tamulus stings in the Mahad region was about $30 \% .^{1-5}$ We have studied this acute medical emergency since 1976. Our clinical observations and knowledge of the pathophysiology of scorpion stings in humans and dogs led to the use of vasodilators and calcium channel blockers which reduced mortality to $2-3 \% .^{46-10}$

Correspondence to Dr H S Bawaskar, Bawaskar Hospital and Research Centre, Mahadi Raigad, Maharashtra, India 402301

Accepted for publication 10 January 1992
Sixty two patients stung by red scorpions (Mesobuthus tamulus) were admitted to our hospital. Soon after being stung 44 patients had vomiting, profuse sweating, hypersaliva- tion, priapism, and mild local pain at the site of the sting that were suggestive of autonomic storm. The other 18 had excruciating pain at the site of the sting that radiated to the adjacent dermatomes but no other signs or symptoms of systemic involvement. Local pain was treated by injecting $0.1-0.2 \mathrm{ml}$ dehydroemetine $(0.03 \%)$ at the site of the sting. Radiation of pain usually prevents patients from identifying the site, but the sting causes local sweating and a punctate haemorrhagic spot in subcutaneous tissue or skin resulting from rupture of the capillaries by the sharp sting. The 44 patients with systemic involvement were admitted and the following were closely monitored: heart rate, blood pressure, persistence of parasternal systolic lift, systolic murmur, gallops, rales, priapism, the appearance of the skin, and the temperature of the extremities. They were divided into three groups with different major clinical features: (a) hypertension; (b) tachycardia; and (c) pulmonary oedema.

\section{HYPERTENSION}

Eighteen patients had hypertension, loud protodiastolic gallop, a transient apical 2/6 systolic murmur of papillary muscle dysfunction, and systolic parasternal lift. They seemed frightened and had prominent eyes and a puffy face. The children were confused and agitated and looked lethargic. In two patients in this group pulmonary oedema subsequently developed.

\section{TACHYCARDIA}

Supraventricular atrial tachycardia (130-180 beats/min) with fast, thready peripheral pulsations and cold extremities developed in 15 children, 5-7 hours after they were stung. There was an improvement in clinical signs with an increase in tissue perfusion within 6-8 hours of treatment with oral prazosin alone (table). Hypovolaemia was corrected by oral rehydration solution. Agitated, confused and non-cooperative patients were given a $5 \%$ dextrose saline drip.

\section{PULMONARY OEDEMA}

Eleven patients had acute pulmonary oedema, tachycardia, cold extremities, ashen grey conjuctivae, tongue, and lips and fingers and toes that looked frostbitten because of severe vasoconstriction. Such patients usually presented later (table) than the other two groups. Two 
Clinical manifestations

\begin{tabular}{lccc}
\hline Data & Hypertension & Tachycardia & Pulmonary oedema \\
\hline Number of patients & $18(11 \mathrm{M:}: 7 \mathrm{~F})$ & $15(8 \mathrm{M}: 7 \mathrm{~F})$ & $11(6 \mathrm{M}: 5 \mathrm{~F})$ \\
Age (yr) & $2-72(39)$ & $1.9-11(9)$ & $9 \cdot 50(22)$ \\
Interval between sting and admission to hospital (h) & $1 \cdot 5-65(3)$ & $1-24(5 \cdot 7)$ & $2-52(11 \cdot 6)$ \\
Blood pressure (mm Hg) & $130 / 90-220 / 140$ & $60 / 90-110 / 90$ & $90 / 70$ unrecordable (PCF) \\
Heart rate (beats/min) & $54-150(87)$ & $130-180(154)$ & $83-150(125)$ \\
Interval between treatment and the start of clinical & $4-20(13.6)$ & $6-18(12)$ & $10-24(16)$ \\
$\quad$ improvement (h) & 4 & \\
\hline
\end{tabular}

Mean is given in parentheses. PCF, peripheral circulatory failure.

of these patients (aged 10 and 25 years) sought help 12 and 4.5 hours after being stung. They had life-threatening massive pulmonary oedema and were cyanosed and coughing up pinkish froth through their mouths and nostrils. The electrocardiographic findings are shown in the figure.

A 25 year old man, who was brought in three days after the sting, had right-sided hemiplegia preceded by pulmonary oedema. A 2 year old girl became unconscious 14 hours after the sting. She had generalised convulsions, pinpoint pupils that reacted poorly to light, undetectable peripheral pulses and blood pressure, and moist rales. The electrocardiogram showed a heart rate of 215 beats $/ \mathrm{min}$, a left anterior hemiblock, a low voltage pattern, and ST segment depression of $5 \mathrm{~mm}$ in leads V2, V3, and V4.

Sixteen patients with hypertension on admission were given a single dose of $5 \mathrm{mg}$ sublingual nifedipine and oral prazosin $(250 \mu \mathrm{g}$ to children and $500 \mu \mathrm{g}$ to adults). Prazosin was repeated six hourly until the extremities were cold (table). The blood pressure in the remaining two patients with hypertension was controlled with sublingual nifedipine alone; the dose was repeated to control rebound hypertension. Three hours later despite control of arterial pressure pulmonary oedema developed in these two patients who recovered after additional treatment with oral prazosin. Patients with tachycardia were treated with prazosin alone and hydration therapy. Those with pulmonary oedema were propped up and given intravenous aminophylline, sodium bicarbonate, oral prazosin, and oxygen by mask. Two of these patients had life-threatening massive pulmonary oedema. They were treated with an intravenous sodium nitroprusside drip. The patient who died had severe pulmonary oedema, tachycardia, convulsions, pin-point poorly reacting pupils, and peripheral circulatory failure. He was treated with intravenous chlorpromazine, aminophylline, sodium bicarbonate, fursemide (to reduce the preload), oxygen by mask, and a 5\% dextrose infusion, but he died of a cardiac arrest.

\section{Discussion}

This was an observational study rather than a strict scientific trial. Because mortality is so high in patients with cardiological symptoms and treatment reduced it to $1.6 \%$ we believe that it would be unethical to withold treatment.

Scorpion stings occur in tropical and subtropical regions and are common in rural India. ${ }^{11-15}$ The haemodynamic and myocardial effects of scorpion venom have been reported

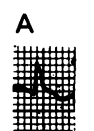

।

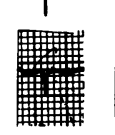

aVR

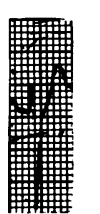

V1

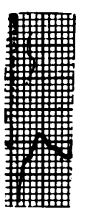

V4
II
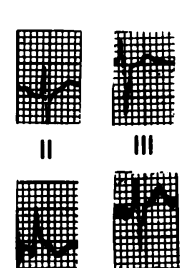

III

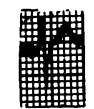

aVL aVF

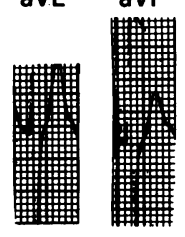

V2 V3

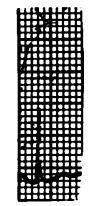

V5

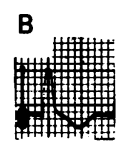

1

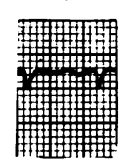

aVR

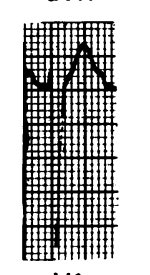

V1

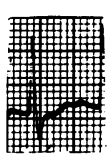

V4

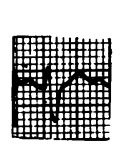

II

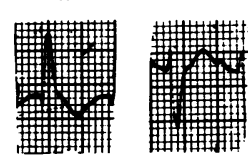

aVL

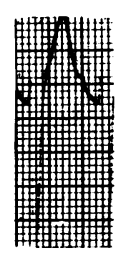

V2

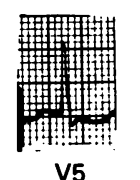

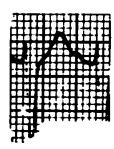
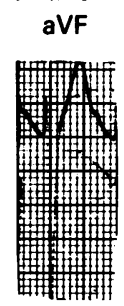

V3

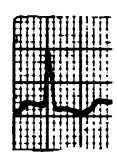

v6
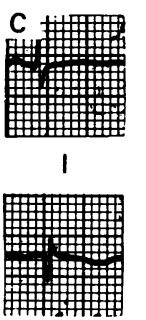

aVR

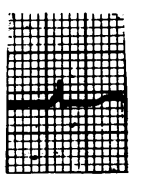

V1

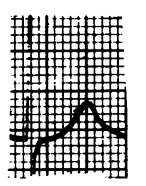

V4

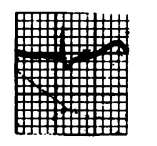

II

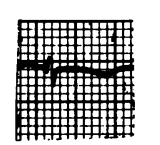

aVL

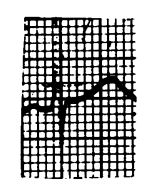

V2

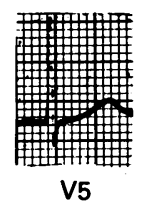

V5

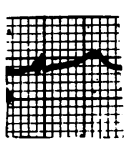

III

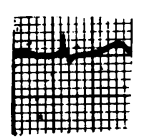

aVF

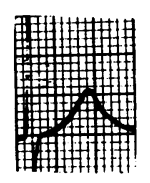

V3

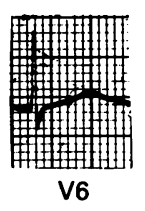

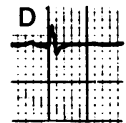

I
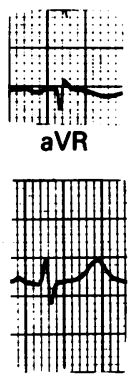

V1

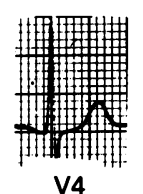

V4

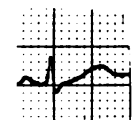

II

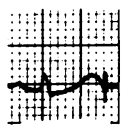

III

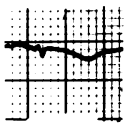

aVL
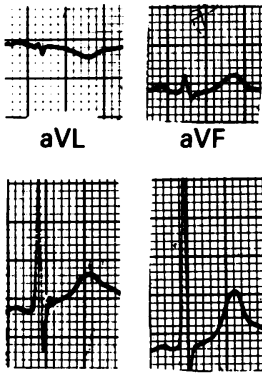

V2
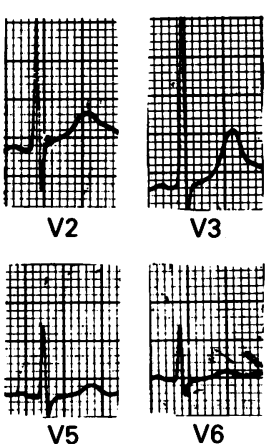

Electrocardiograms from a 10 year old boy who presented with pulmonary oedema 12 hours after a scorpion sting. (A) On admission there was left axis deviation and ST segment elevation and T inversion in leads I and aVL. (B) Twelve hours after admission there was left bundle branch block with left axis deviation and associated $T$ inversion in leads $I, a V L$, and V5-V6. (C) On day 11 there was there was regression of acute changes. Note right axis deviation and tall $R$ waves in right precordial leads, with $T$ inversion in $a V L(Q T 0.48 \mathrm{~s})$. (D) After five weeks the electrocardiograms were essentially similar to $C$. 
in experimental animals as well as in humans. ${ }^{1016-18}$ The red scorpion (Mesobuthus tamulus) was responsible for the stings reported here. Its venom is a potent stimulator of the autonomic nervous system causing a sudden outpouring of endogenous catecholamines into the circulation. ${ }^{1920}$ The venom initially causes transient cholinergic stimulation (vomiting, profuse sweating, bradycardia, priapism, hypersalivation, and hypotension) which is followed by sustained adrenergic hyperactivity (hypertension, tachycardia, and myocardial failure). The adrenergic phase but not the cholinergic phase is a dose dependent phenomenon. ${ }^{2122}$ On the basis of clinical manifestations and known pathophysiology of scorpion envenomation we devised an approach to management that did not use antivenin. We treated patients in our facility with what was available to us. We believe that transporting these patients to the nearest big hospital can contribute to their death. ${ }^{4}$ Nifedipine, a calcium channel blocker, is useful for the immediate treatment of hypertension and helps to reduce the myocardial contractility enhanced by autonomic stimulation. ${ }^{823}$ In addition nifedipine may protect the heart muscle from the toxic effects of scorpion venom. ${ }^{24}$ Experimental studies showed that myocardial damage after a scorpion envenomation is caused by an influx of calcium ions into the heart muscle cells. ${ }^{25}$ Sudden rebound of hypertension in some patients can be explained by recurrent envenoming. Prazosin, a post synaptic $\alpha$ blocker, is known to reduce preload and left ventricular impedance. Its hypotensive action may also be due to inhibition of adrenaline synthesis at the betahydroxylation step. ${ }^{26}$ Thus prazosin blocks the action of adrenaline. ${ }^{2728}$ Plasma renin activity was not significantly increased in response to blood pressure lowering action of prazosin. ${ }^{26}$ Nifedipine alone does not prevent myocardial damage unless the peripheral action of venom is blocked by the sympathetic $\alpha$-blocker, prazosin. ${ }^{29}$ Although blood pressure was controlled by nifedipine, subsequent myocardial failure responded only after the addition of oral prazosin. Most of the electrocardiographic abnormalities in human scorpion sting, including ST-T changes, closely resemble the electrocardiograms in patients with congenital QT interval syndrome. ${ }^{30}$ The outpouring of catecholamines in response to the scorpion sting is probably a major factor in the pathogenesis of ST-T changes. ${ }^{31}$ The possibility of a direct effect of the toxin on the myocardium, however, cannot be excluded. ${ }^{32}$

In dogs various metabolic disturbances caused by scorpion venom were reversed by the specific scorpion antivenin essentially through the release of insulin. ${ }^{33}$ Prazosin inhibits the suppression of insulin secretion caused by scorpion envenoming. ${ }^{34}$ As a consequence of this action it helps to reverse the metabolic changes and arrest myocardial damage caused by liberated free fatty acids and phospholipids. ${ }^{7}$ We have found that the combination of nifedipine and prazosin is a pharmacological antidote to the action of venom. This treatment is quick acting, easily available, relatively cheap and does not risk anaphylaxis. ${ }^{35}$
We thank Professor B B Gaitonde and Professor D A Warrell for their help in the preparation of this paper and Mr Sanjay Pingale for typing it.

1 Mundle PM. Scorpion sting. Br Med J 1961;i:1042.

2 Bawaskar HS. Scorpion sting and cardiovascular complications. Indian Heart J 1977;29:228.

3 Gaitonde BB, Jadhav SS, Bawaskar HS. Pulmonary oedema after scorpion sting. Lancet 1978;i:445-6.

4 Bawaskar HS. Diagnostic cardiac premonitary signs and symptoms of red scorpion sting. Lancet 1982;ii:552-4.

5 Bawaskar HS. Scorpion sting. Trans $R$ Soc Trop Med Hyg 1984;78:414-5.

6 Bawaskar HS, Bawaskar PH. Prazosin in the management of cardiovascular manifestations of scorpion sting. Lancet 1986;i:510-1.

7 Bawaskar HS, Bawaskar PH. Prazosin for vasodilator treatment of acute pulmonary oedema. Ann Trop Med Parasitol 1987;81:719-23.

8 Bawaskar HS, Bawaskar PH. Stings by red scorpions (Buthotus tamulus) in Maharashtra State, India. A clinical study. Trans $R$ Soc Trop Med Hyg 1989;83:858-60.

9 Gueron $M$, Sofer S. Vasodilators and calcium blocking agents as treatment of cardiovascular manifestations of human scorpion envenomation. Toxicon 1990;28:127-8.

10 Gueron M, Adolph R, Grupp I, Grupp O, Gabel M, Fowler NO. Hemodynamic and myocardial consequences of scorpion venom. Am J Cardiol 1980;45:979-86.

11 Poonking T. Myocarditis from scorpion stings. Br Med J 1963;i:374-7.

12 Waterman JA. Some notes on scorpion poisoning in Trinidad. Trans R Soc Trop Med Hyg 1938;31:607-24.

13 Amitai Y, Mines Y, Aker M, Goiten K. Scorpion sting in children. A revise of 51 cases. Clin Pediat 1984;24:136-40.

14 Rimsza ME, Zimmerman DR, Bergeson PS. Scorpion sting envenomation. Pediatrics 1980;66:298-302.

15 Efrati P. Poisoning by scorpion stings in Israel. Am J Trop Med 1949;29:249-57.

16 Sofer S, Gueron $M$. Respiratory failure in children following envenomation by the scorpion Leiurus quinquestriatus hemodynamic and neurological aspect. Toxicon 1988 26:931-9.

17 Gueron M, Margulis G, Sofer S. Echocardiographic and radionuclide angiographic observations following scorpion envenomation. By Leiurus quinquestriatus. Toxicon 1990;28:1005-9.

18 Lima EG, Freire-Maia L. Cardiovascular and respiratory effects induced by intracerebroventricular injection of scorpion toxin (Tityustoxin) in the rat. Toxicon 1977; scorpion to

19 Moss J, Thoa NB, Kopin IJ. On the mechanism of scorpion toxin induced release of norepinephrine from peripheral adrenergic neurones. J Pharmacol Exp Ther 1974;190 39-48.

20 Choudhury L, Ganguly DK. Some cardiovascular effects of crude scorpion venom. Indian J Med Res 1978;68:15-8.

21 Ramchandran LK, Agarwal OP, Achyuthan KE, Chaudhury L, Vedasiromani JR, Ganfuly DK. Fractionations and biological activities of venoms of the Indian scorpion Buthus tamulus and Herometrus bengalensis. Indian $J$ Biochem Biophys 1986;23:355-8.

22 Bawaskar HS, Bawaskar PH. Consecutive stings by red scorpions evoke severe cardiovascular manifestations in the first, but not in the second victim. A clinical observation. J Trop Med Hyg 1991;94:231-3.

23 Urthaler F. Review: Role of calcium channel blocker in clinical medicine. Am J Med Sci 1986;292:217-30.

24 Sofer S, Gueron $M$. Vasodilators and hypertensive encephalopathy following scorpion envenomation in children. Chest 1990;97:118-20.

25 Yarom $\mathbf{R}$, Brun $\mathrm{K}$. Changes in myocardium following scorpion venom injection. J Mol Cell Cardiol 1971;2: $177-9$.

26 Graham RM, Pettinger WA. Drug therapy prazosin. $N$ Engl J Med 1979;300:232-5.

27 Lowenstein J, Steel JM. Appraisal and reappraisal of cardiac therapy prazosin. Am Heart J 1978;95:262-5.

28 Graham RM, Oates HF, Stoker LM, Stokes GS. Alph blocking action of the antihypertensive agent prazosin. $J$ Pharmacol Exp Ther 1977;201:747-52.

29 Freire-Maia L, Pinto GI, Franco I. Mechanism of the cardiovascular effects produced by purified scorpion toxin in the rat. $J$ Pharmacol Exp Ther 1974;188:207-13.

30 Gueron M, Ovsyshcher I. Cardiovascular effects of scorpion venoms, insect, poison, allergens and other invertebrate venom. In: Tu A, ed. Handbook of Toxin. Volume 2. New York: Marcel Dekker, 1984:639-54.

31 Raab W. Key position of catecholamines in functional and degenerative cardiovascular pathology. Am J Cardiol 1960;5:571-8.

32 Ismail M, ABD-Elsalam MA. Are the toxicological effects of scorpion envenomation related to tissue concentration? scorpion envenomation
Toxicon 1988;26:233-56.

33 Murthy KRK, Konkonkar RL, Zare AM, Malthi A Balasubramanian P, Yeolekar ME. Release of metabolic and electrocardiographic changes by scorpion antivenin administration in experimental myocarditis induced by administration in experimental myocarditis induced by Indian red scorpion (Family Buthidae) venom (abstr 286).
Singapore: 10th Congress on animal plant and microbial Singapore: 10th

34 Johnson DG, Petal HD. Inhibition of insulin release by scorpion toxin in rat pancreatic islets. Diabetes 1976;25:198-201.

35 Bawaskar HS, Bawaskar PH. Short report-Treatment of envenoming by Mesobithus tamulus (Indian red scorpion). Trans $R$ Soc Trop Med Hyg (in press). 